\title{
IN VITRO PHARMACOLOGICAL SCREENING METHODS FOR ANTI-INFLAMMATORY AGENTS
}

\author{
JIJITH US ${ }^{1,2}$, JAYAKUMARI $\mathbf{S}^{1 *}$
}

${ }^{1}$ Department of Pharmacognosy, School of Pharmaceutical Sciences, Vels Institute of Science Technology and Advanced Studies, Pallavaram, Chennai, Tamil Nadu, India. ${ }^{2}$ Department of Pharmacognosy, College of Pharmaceutical Sciences, Government Medical College, Kozhikode - 673 008, Kerala, India. Email: nisajayaa@gmail.com

Received: 10 October 2018, Revised and Accepted: 11 December 2018

\begin{abstract}
Context: The development of in vitro methods is important in drug discovery process due to the restriction of animal use in the pharmacological screening process.
\end{abstract}

Objective: The objective of the review was to understand the in vitro pharmacological screening methods for anti-inflammatory agents.

Methods: The present review details various in vitro methods available for the screening of activity of therapeutic agents against inflammation.

Results: Inhibition and measurement of nitric oxide production, mast cell degranulation, leukocyte adhesion assay, platelet-neutrophil adhesion assay, lipopolysaccharide-induced response assay, $\mathrm{N}$-formyl-methionyl-leucyl-phenylalanine-induced $\mathrm{O}_{2}$ generation by polymorphonuclear cells, and cyclooxygenase assays are discussed in this review.

Conclusions: These methods help to understand the real mechanism of inflammation and mediators involved in this process and help to identify new compounds possessing the anti-inflammatory activity.

Keywords: Reactive oxygen species, Polymorphonuclear cells, Cytokines, Cyclooxygenase, Macrophages, Neutrophil.

(C) 2018 The Authors. Published by Innovare Academic Sciences Pvt Ltd. This is an open access article under the CC BY license (http://creativecommons. org/licenses/by/4. 0/) DOI: http://dx.doi.org/10.22159/ajpcr.2018.v11s4.31709

\section{INTRODUCTION}

Inflammation is the process in which a series of reactions occur as a part of body's defense mechanism against various endogenous and exogenous stimuli. According to its length, inflammation is classified as acute and chronic. Healing, a process which is not completed without inflammation, is an immune response of the body; to remove foreign body from the body, it may be living organism, chemical or physical stimuli. The main symptoms of inflammation are pain, swelling, redness, heat, and immobility [1]. The major components of inflammation are categorized as vascular and cellular changes. Vascular changes involve increased blood flow, momentary vasoconstriction of blood vessels, and vasodilation of arterioles and venules; increased permeability leads to release of chemical mediators, swelling, and increased viscosity. Cellular changes involve migration of leukocyte from circulation to the degradation of bacteria. These changes could be monitored for the investigation of anti-inflammatory activity of a compound [2]. The major signs of the inflammation are pain, swelling, and fever. Large varieties of anti-inflammatory drugs are available in the market. However, none of these drugs are free from side effects. The development of less gastric irritation producing drugs is important. In addition to in vivo method, some standard primary assays are available to investigate the anti-inflammatory activity in drug discovery process. The development of in vitro methods is important in drug discovery process due to the restriction of animal use in the pharmacological screening process. In vitro assays are simple and not complex like in vivo methods. Most of these methods mimic in vivo response and are now widely used for the monitoring and development of new agents against inflammation [3].

\section{INHIBITION OF NITRIC OXIDE (NO) PRODUCTION IN MOUSE MACROPHAGES}

NO acts as important mediators in inflammatory process. During inflammation, large amount of NO is produced. Hence, inhibition of NO production property of a compound is one of the important criteria in the pharmacological screening of anti-inflammatory activity [4]. A standard anti-inflammatory steroid drug like hydrocortisone is taken as positive control in this type of assay. The test compound is dissolved in dimethyl sulfoxide and added to cell culture. Here, macrophages are obtained by intraperitoneal injection of thioglycollate broth to mice. After 4-5 days of injection, peritoneal macrophages are harvested and proceeded according to Ding's procedure. Incubation of cells is then carried out in 96-well plates with IFN gamma with or without the agent under test [5].

The presence of nitrite in a medium is used as an indicator of NO production [5]. In the presence of oxygen, NO is converted to nitrite, which could be measured using the Griess reaction. The Griess reaction is the easiest and simplest colorimetric assay for the determination of nitrite [6]. Here, Griess reagent is placed into both the culture media containing test substance and without the test substance. The plates are incubated for $10 \mathrm{~min}$ at $37^{\circ} \mathrm{C}$ and are read at $570 \mathrm{~nm}$ with a spectrophotometer. The nitrite concentrations are estimated using a calibration curve of sodium nitrite [7].

\section{MAST CELL DEGRANULATION}

During the inflammation and allergy, the mast cells are degranulated. The degree of this degranulation is a significant criterion in the pharmacological screening process of therapeutic agents against inflammation [8]. The mast cell degranulation models are widely utilized for this study. In addition to degranulation, histamine and beta-hexosaminidase are also released, which stimulate the metabolic process of arachidonic acid. The measurement of such substances is also helpful in the pharmacological screening process for new anti-inflammatory agents. There are several methods employed to detect degranulation of mast cells and release of mediators. They include enzyme-linked immunosorbent assays (ELISAs) or colorimetric assays. Colorimetric assay to measure the inflammatory mediators is rapid and 
sensitive. Another reported method is based on the particle analysis of granules in RBL-2H3 cells [9]. Fluorometric assay of histamine [10] and flow cytometric Annexin-V binding assay [11] are also available for this purpose. The percentage release of inflammatory mediator is the index of anti-inflammatory activity.

\section{ADHESION ASSAY}

Adhesion of leukocytes is an important cellular stage during the inflammation process [12]. Adhesion assay involves the estimation of vascular proteins vascular cell adhesion molecule 1, intercellular adhesion molecule 1 , and E-selectin in primary cells derived from human umbilical vein endothelial cells and human microvascular endothelial cell line [13]. Human dermal microvascular endothelial cells are the most suitable to predict in vivo situations in the best manner [14]. In the adhesion assay, tumor necrosis factor (TNF)-alpha stimulated cell lines are incubated with test drug [15]. The procedure involves labeling of neutrophil with appropriate fluorescent materials and allowing adhering. Finally, the measurement of fluorescence is carried out at $485 \mathrm{~nm}$ in an ELISA reader [14].

\section{Platelet-neutrophil adhesion assay}

In this method, neutrophils are mixed with thrombin-activated platelets, which are previously incubated with drugs for $10 \mathrm{~min}$ [16]. If the test drug inhibits the adhesion of neutrophils, it indicates an antiinflammatory activity of the tested drug. A control is also carried out along with the test sample [14]

\section{Neutrophil adhesion to hypoxia-stimulated porcine aorta}

Here, the porcine aorta is stimulated by placing them into phosphatebuffered saline gassed with $\mathrm{N}_{2}$ and placed between steel plates having holes and Teflon blocks. The drug under test and neutrophils are added on the side of the plates and incubated for $90 \mathrm{~min}$. The measure of the adhesion of neutrophils in the presence of drug is carried out. A control with the absence of drug is also carried out [14]

\section{LIPOPOLYSACCHARIDE (LPS)-INDUCED RESPONSE ASSAY}

Expression of inducible NO synthase (iNOS) protein, NO production, TNF-alpha expression, and p38 MAP Kinase (MAPK) by LPS in mouse macrophages can be utilized for screening anti-inflammatory activity [17]. When cell lines are treated with LPS, it induces the production of iNOS proteins, NO, TNF-alpha expression, and MAPK protein expression; these can be measured by western blot method [18]. This should be performed with and without the presence of the test drug. In the presence of existing anti-inflammatory drugs, a reduction in the production of these substances will be noted. The degree of inhibition could be compared with standard drugs.

\section{N-FORMYL-METHIONYL-LEUCYL-PHENYLALANINE (FMLP)-INDUCED $\mathrm{O}_{2}$ GENERATION BY POLYMORPHONUCLEAR CELLS (PMNS)}

Many compounds are generated during inflammatory process. FMLP induces reactive oxygen species (ROS). ROS is one of the substances whose concentration is increased in leukocytes, PMNs, monocytes, and vascular endothelial cells during inflammation [19]. Generation of such a substance may contribute to various degenerative diseases such as arthritis. Estimation of such a substance is one of the important criteria for the pharmacological screening of anti-inflammatory agent. The degree of the ability to decrease the production of ROS reflects the antiinflammatory activities of new compounds.

\section{CYCLOOXYGENASE (COX) ASSAYS}

The COX enzymes convert arachidonic acid to prostaglandins [20]. COX has two forms, COX-1 and COX-2 [21]. Here, COX-1 is constitutive, which is important in physiological functions, whereas COX-2 is inducible and involved in pathological function [22]. In the inflammatory process, this enzyme has an important role. Hence, the estimation of the end product such as prostaglandin concentration will be helpful in the pharmacological screening of anti-inflammatory agents. The various in vitro methods are employed for this purpose.

\section{COX-1 assay}

In this assay, the sample solution was mixed with L-adrenaline-Dhydrogen tartrate and hematin. Then, the incubation of the mixture is carried out with COX-1. Then, the arachidonic acid is added and incubated for $20 \mathrm{~min}$ at $37^{\circ} \mathrm{C}$. Addition of formic acid to the mixture stops the incubation. Using enzyme immunoassay, measure the concentration of prostaglandin 2 [23].

\section{coX-2 assay}

The basis of this assay is that $\mathrm{N}, \mathrm{N}, \mathrm{N}^{\prime}, \mathrm{N}^{\prime}$-tetramethyl-p-phenylenediamine (TMPD) gets oxidized when the reduction of prostaglandin-G2 to prostaglandin- $\mathrm{H} 2$ occurs [24]. The oxidation velocity of TMPD is measured spectrophotometrically. The sample is introduced to the mixture of sodium phosphate buffer, gelatin, hematin, and purified COX-2. This mixture is pre-incubated with arachidonic acid before the addition of TMPD. The percentage inhibition is determined by measuring the absorbance at $610 \mathrm{~nm} \mathrm{[25].}$

\section{CONCLUSIONS}

From the literature review, it can be seen that several in vitro methods are developed for the pharmacological screening of anti-inflammatory activity. Many of the methods reflect in vivo performance. These methods help to understand the real mechanism of inflammation and to identify new compounds possessing the anti-inflammatory activity. It is very difficult to develop single in vitro method for anti-inflammatory activity. Even in future, the mentioned method will accelerate the antiinflammatory drug development process.

\section{REFERENCES}

1. Koh TJ, DiPietro LA. Inflammation and wound healing: The role of the macrophage. Expert Rev Mol Med 2011;13:e23.

2. Nourshargh S, Alon R. Leukocyte migration into inflamed tissues. Immunity 2014;41:694-707.

3. Hughes JP, Rees S, Kalindjian SB, Philpott KL. Principles of early drug discovery. Br J Pharmacol 2011;162:1239-49.

4. Joo T, Sowndhararajan K, Hong S, Lee J, Park SY, Kim S, et al. Inhibition of nitric oxide production in LPS-stimulated RAW 264.7 cells by stem bark of Ulmus pumila L. Saudi J Biol Sci 2014;21:427-35.

5. Lin QY, Jin LJ, Cao ZH, Xu YP. Inhibition of inducible nitric oxide synthase by acanthopanax senticosus extract in RAW264.7 macrophages. J Ethnopharmacol 2008;118:231-6.

6. Wen Q, Paik DC. Using the griess colorimetric nitrite assay for measuring aliphatic $\beta$-nitroalcohols. Exp Eye Res 2012;98:52-7.

7. Bradford MM. A rapid and sensitive method for the quantitation of microgram quantities of protein utilizing the principle of protein-dye binding. Anal Biochem 1976;72:248-54.

8. Cidade AF, Vasconcelos PA, Silva DP, Florentino IF, Vasconcelos GA, Vaz BG, et al. Design, synthesis and pharmacological evaluation of new anti-inflammatory compounds. Eur J Pharmacol 2016;791:195-204.

9. Huang L, Pi J, Wu J, Zhou H, Cai J, Li T, et al. A rapid and sensitive assay based on particle analysis for cell degranulation detection in basophils and mast cells. Pharmacol Res 2016;111:374-83.

10. Shore PA, Burkhalter A, Cohn VH Jr. A method for the fluorometric assay of histamine in tissues. J Pharmacol Exp Ther 1959;127:182-6.

11. Demo SD, Masuda E, Rossi AB, Throndset BT, Gerard AL, Chan EH, et al. Quantitative measurement of mast cell degranulation using a novel flow cytometric annexin-V binding assay. Cytometry 1999;36:340-8.

12. Langer HF, Chavakis T. Leukocyte-endothelial interactions in inflammation. J Cell Mol Med 2009;13:1211-20.

13. Wildner O, Lipkow T, Knop J. Increased expression of ICAM-1, E-selectin, and VCAM-1 by cultured human endothelial cells upon exposure to haptens. Exp Dermatol 1992;1:191-8.

14. Schön MP, Krahn T, Schön M, Rodriguez ML, Antonicek H, Schultz JE, et al. Efomycine M, a new specific inhibitor of selectin, impairs leukocyte adhesion and alleviates cutaneous inflammation. Nat Med 2002;8:366-72.

15. Håkanson R, Rönnberg AL. Improved fluorometric assay of histamine: Condensation with O-phthalaldehyde at -20 degrees C. Anal Biochem 1974;60:560-7. 
16. Taylor ML, Ilton MK, Misso NL, Watkins DN, Hung J, Thompson PJ, et al. The effect of aspirin on thrombin stimulated platelet adhesion receptor expression and the role of neutrophils. $\mathrm{Br} \mathrm{J}$ Clin Pharmacol 1998;46:139-45.

17. Lee MH, Lee JM, Jun SH, Ha CG, Lee SH, Kim NW, et al. In-vitro and in-vivo anti-inflammatory action of the ethanol extract of trachelospermi caulis. J Pharm Pharmacol 2007;59:123-30.

18. Reis J, Guan XQ, Kisselev AF, Papasian CJ, Qureshi AA, Morrison DC, et al. LPS-induced formation of immunoproteasomes: TNF- $\alpha$ and nitric oxide production are regulated by altered composition of proteasomeactive sites. Cell Biochem Biophys 2011;60:77-88.

19. Chen Y, Junger WG. Measurement of oxidative burst in neutrophils. Methods Mol Biol 2012;844:115-24

20. Chow LW, Yip AY, Chu WP, Loo WT, Toi M. Bone metabolism and quality-of-life of postmenopausal women with invasive breast cancer receiving neoadjuvant hormonal therapy: Sub-analyses from celecoxib anti-aromatase neoadjuvant (CAAN) trial. J Steroid Biochem Mol Biol 2011;125:112-9.

21. Sung-Hwan E, Eun-Hye L, Kunbawui P, Ji-Young K, Poong-Ho K, Won-Kyo J, et al. Eckol from Eisenia bicyclis inhibits inflammation through the Akt/NF-kb signaling in propionibacterium acnes-induced human keratinocyte hacat cells. J Food Biochem 2016;41:e12312.

22. Mohammed NA, Abd El-Aleem SA, El-Hafiz HA, McMahon RF. Distribution of constitutive (COX-1) and inducible (COX-2) cyclooxygenase in postviral human liver cirrhosis: A possible role for COX-2 in the pathogenesis of liver cirrhosis. J Clin Pathol 2004;57:350-4.

23. Resch M, Steigel A, Chen ZL, Bauer R. 5-lipoxygenase and cyclooxygenase-1 inhibitory active compounds from Atractylodes lancea. J Nat Prod 1998;61:347-50.

24. Petrovic N, Murray M. Using N,N,N',N'-tetramethyl-pphenylenediamine (TMPD) to assay cyclooxygenase activity in vitro. In: Armstrong D, editors. Advanced Protocols in Oxidative Stress II. Methods in Molecular Biology (Methods and Protocols). Vol. 594. Totowa, New Jersey: Humana Press; 2010

25. Copeland RA, Williams JM, Giannaras J, Nurnberg S, Covington M, Pinto D, et al. Mechanism of selective inhibition of the inducible isoform of prostaglandin G/H synthase. Proc Natl Acad Sci U S A 1994;91:11202-6. 